\title{
Rheological Properties of Cuttlefish and Squid Raw Meat
}

\author{
Yoshinori Mochizuki, ${ }^{* 1}$ Haruo Mizuno, ${ }^{* 1}$ Hiroo Ogawa, ${ }^{* 1}$ Kazuo Ishimura, ${ }^{* 2}$ Hideki Tsuchiya, ${ }^{* 2}$ \\ Misako Fukuzawa, ${ }^{* 1}$ and Naomichi Iso*1 \\ ${ }^{* 1}$ Department of Food Science and Technology, Tokyo University of Fisheries, Minato, Tokyo 108, Japan \\ ${ }^{* 2}$ Shiogama Laboratory, Kyokuyo Co., L.td., Shinhama, Shiogama, Miyagi 985, Japan \\ (Received December 16, 1993)
}

Rupture tests and stress relaxation tests were carried out to distinguish between raw meat of a cuttlefish, "kou ika" Sepia esculenta, and that of four squids, "yari ika" Loligo bleekeri, "Argentine matsu ika" Illex argentinus, "surume ika" Todarodes pacificus, and "New Zealand surume ika" Nototodaus sloani sloani, respectively. The rupture force and the rupture work were positively proportional strength and rupture power could be estimated from the parameters obtained through the rupture tests. Linear relationships with high correlation coefficients were obtained between the rupture power as well as relaxation time and the water content or crude protein content of samples. Each "ika" raw meat of the different species could thus be distinguished from its rheological properties.

Key words: cuttlefish, squid, meat, rheology, rupture strength, stress relaxation

Cuttlefish and squid, called "ika" in Japanese, are one of the most popular seafoods in Japan. In general the mantle of cuttlefish are mainly consumed as "sashimi" which is small slices of raw meat and as sushi, which is a slice of raw meat on a bite-sized vinegared rice ball.

As is typical for a traditional food, we have received many reports on processing and tasting. ${ }^{1,2)}$ For "surume ika", we know the mantle structure, ${ }^{3)}$ the rheological properties of the meat paste, the setting and jelly strength, ${ }^{4,5}$ the toughness for boiled meat with several reagents, ${ }^{6}$ the changes in texture and decomposition of the proteins cured in sake lees, and the decrease in hardness during curing in sake lees. ") However, the texture of the raw meat and the different textures of several species of "ika" have not been studied. What constitutes a good texture?

This study investigated the rheological properties of raw meat for several species of ika using a new texture profile.

\section{Materials and Methods}

Materials

The cuttlefish "kou ika" Sepia esculenta and four squids, "yari ika"
Loligo bleekeri, "Argentine matsu ika" Illex argentinus, surume ika Todarodes pacificus, and "New Zealand surume ika" Nototodaus sloan sloani were used as samples. They were immediately frozen after fishing transported, and kept in our laboratry at $-20^{\circ} \mathrm{C}$ until use. They were of commercial size as listed in Table 1. Mantles with surface skin were removed from the samples after thawing at room temperature

Measurement of Composition

The water content of the materials was measured by a drying method at $105^{\circ} \mathrm{C}$ with three replicates. The crude fat content was determined by the Soxhlet extration method with an ethyl ether for $18 \mathrm{~h}$. The crude protein content was determined by the Kjeldahl method. The factor 6.25 was used to convert the obtained amount of nitrogen to the crude protein content. These values are shown in Table 1.

\section{Measurement of Rheological Properties}

Three or four rectangular specimens $(c a .3 \times 3 \mathrm{~cm})$ of different thickness were prepared from each mantle of three samples of a cuttlefish and squids for the measurement of rheological properties. The rheological properties were measured at room temperature by using a Tensipresser TTP-50BX. (Taketomo Electric Co., Ltd.) The rupture strength was measured with a conical plunger (angle $45^{\circ}$ ) penetrating at $0.2 \mathrm{~cm} / \mathrm{s}$ of crosshead speed into the samples. In the stress relaxation test, the strain at $20 \%$ depth of sample thickness was kept linear, with a cylindrical (diameter $1.8 \mathrm{~cm}$ ) plunger penetrating at the same crosshead speed. The stress relaxation curves were analyzed by the progressive approximate method based on the Maxwell

Table 1. Composition of the materials

\begin{tabular}{|c|c|c|c|c|c|c|}
\hline Sample name & $\begin{array}{c}\text { Collecting date } \\
\text { and location }\end{array}$ & $\begin{array}{l}\text { Total weight } \\
(\mathrm{g})\end{array}$ & $\begin{array}{l}\text { Mantle thickness } \\
\qquad(\mathrm{cm})\end{array}$ & $\begin{array}{c}\text { Water } \\
(\%)\end{array}$ & $\begin{array}{l}\text { Crude protein } \\
(\%)\end{array}$ & $\begin{array}{c}\text { Crude fat } \\
(\%)\end{array}$ \\
\hline "kou ika" & Jun. 1992 & $240 \pm 12$ & $0.67 \pm 0.18$ & $80.0 \pm 1.2$ & $17.8 \pm 2.1$ & $1.0 \pm 0.1$ \\
\hline Sepia esculenta & Tsu-shima & & & & & \\
\hline "yari ika" & Jun. 1992 & $440 \pm 32$ & $0.60 \pm 0.11$ & $79.4 \pm 1.0$ & $18.6 \pm 1.9$ & $1.1 \pm 0.1$ \\
\hline Loligo bleekeri & East China Sea & & & & & \\
\hline "Argentine matsu ika" & Mar. 1992 & $450 \pm 25$ & $0.50 \pm 0.07$ & $78.0 \pm 0.8$ & $18.4 \pm 1.5$ & $1.2 \pm 0.1$ \\
\hline Illex argentimus & Falkland & & & & & \\
\hline "surume ika" & Aug. 1992 & $490 \pm 48$ & $0.66 \pm 0.13$ & $75.0 \pm 1.1$ & $21.2 \pm 2.2$ & $1.0 \pm 0.1$ \\
\hline Todarodes pacificus & Japan Sea & & & & & \\
\hline "New Zealand surume ika" & Mar. 1992 & $450 \pm 27$ & $0.72 \pm 0.15$ & $77.2 \pm 1.2$ & $20.2 \pm 1.8$ & $1.0 \pm 0.1$ \\
\hline Nototodaus sloani sloani & New Zealand & & & & & \\
\hline
\end{tabular}

The values are expressed as mean $\pm \mathrm{SD}$ of six to nine mantles. 
model. ${ }^{8}$

\section{Results and Discussion}

Definitions of Rupture Strength and Rupture Power

Each mantle of the samples had a different thickness as shown in Table 1. For instance, the mantle of "New Zealand surume ika" was almost 1.5 times thicker than that of "Argentine matsu ika." It was therefore necessary to correct the estimates of the force and work to the mantle thickness due to the great deformational measurement.

The force and work required to rupture the mantle of "matsu ika" are shown in Fig. 1 (top) and (bottom), respectively. The linear relationships between the deformation and the force or the work showed a positive correlation (correlation coefficient: $0.56-0.93$ between the force and deformation, $0.64-0.95$ between the work and deformation). In the other samples, both values for rupturing also showed a similar tendency. The rupture force per $1.0 \mathrm{~cm}$ was thus expressed as the rupture strength. Similarly, the rupture work per second was expressed as the rupture power.

Generally, the structure of the "ika" mantle is very complex, composing the outer skin of four layers, the muscle, and the inner skin. The non-directional net-like layers are placed from the first to the third layer of the outer skin. The outer skin is harder and less elastic than the muscle and the inner skin. ${ }^{3)}$ The measurement must therefore consider the direction, whether measured from the outside or inside.

The repture strength and the rupture power of each sample are shown in Fig. 2 (top) and (bottom). The left bar of each sample shows the value measured from the inside of the mantle and the right one the outside. The values measured on the outside were larger than those on the inside except for "kou ika".

\section{Stress Relaxation Test}

The elastic modulus obtained from the stress relaxation

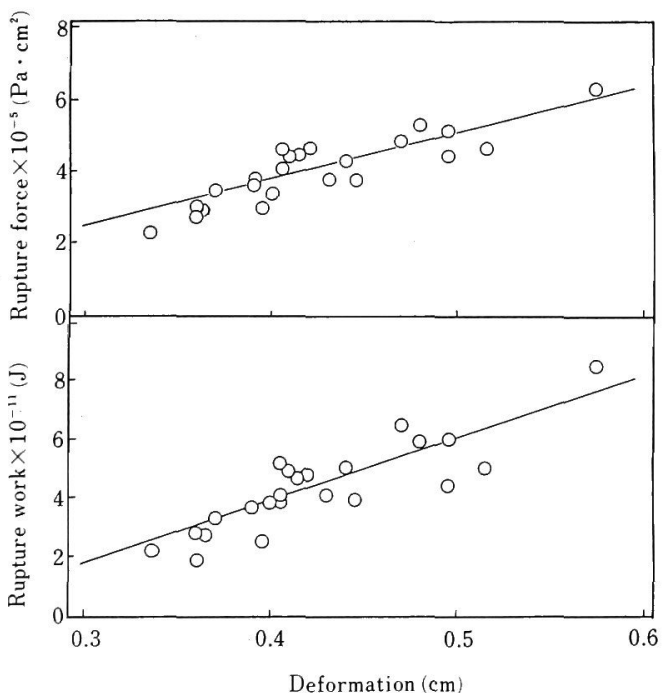

Fig. 1. Relationships between deformation and force or work upon rupturing the raw meat of "matsu ika".

The correlation coefficient between the deformation and the force was 0.895 (top), and between the deformation and the work, 0.888 (bottom). test is shown in Fig. 4 (top). The values measured on the inside of the mantle were larger than those on the outside. This result is contrary to the result of the rupture test. The apparent stress observed was smaller than the actual stress, since both the inner skin and the bottom muscle in the mantle were dilated horizontally when the mantle was compressed from the outside, as shown in the bottom right of Fig. 3.

On the contrary, the outer skin layers and the top muscle were not dilated when the mantle was compressed from the inside, as shown in the bottom left of Fig. 3. The apparent stress observed was close to the actual stress. The rheological

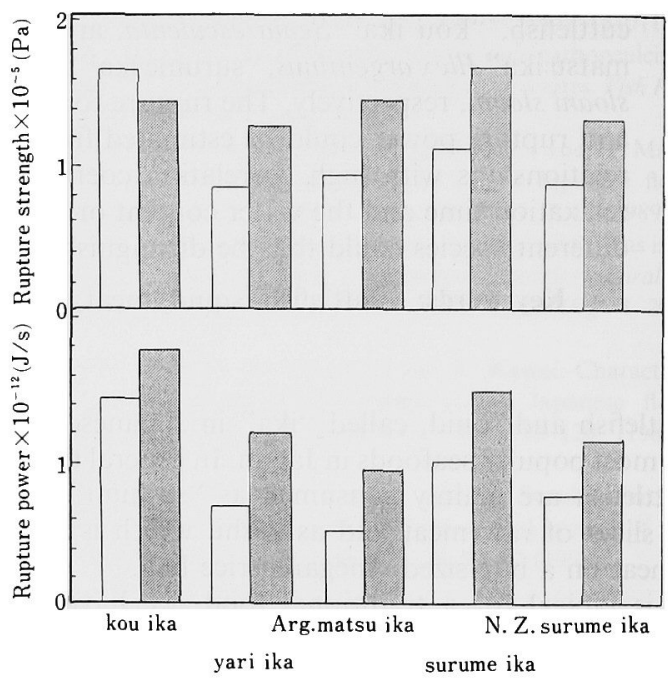

Fig. 2. Estimated values of rupture strength and rupture power of "ika" raw meat.

The rupture strength (top) and the rupture power (bottom) were estimated from the values measured from the inside of the mantle (left bar for each sample) and from the outside of the mantle (right bar for each sample)
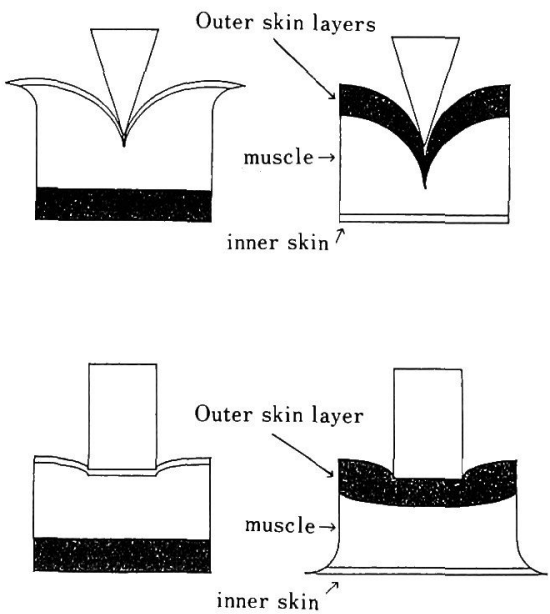

Fig. 3. Schematic sectional view of "ika" raw meat in the rupture test and the stress relaxation test.

The two top views show when the "ika" mantle was compressed from the inside of the mantle (left) or from the outside of the mantle (right) with a conical plunger in the rupture test.

The two bottom views show when the ika mantle was compressed from the inside of the mantle (left) or from the outside of the mantle (right) with a cylindrical plunger in the stress relaxation test. 


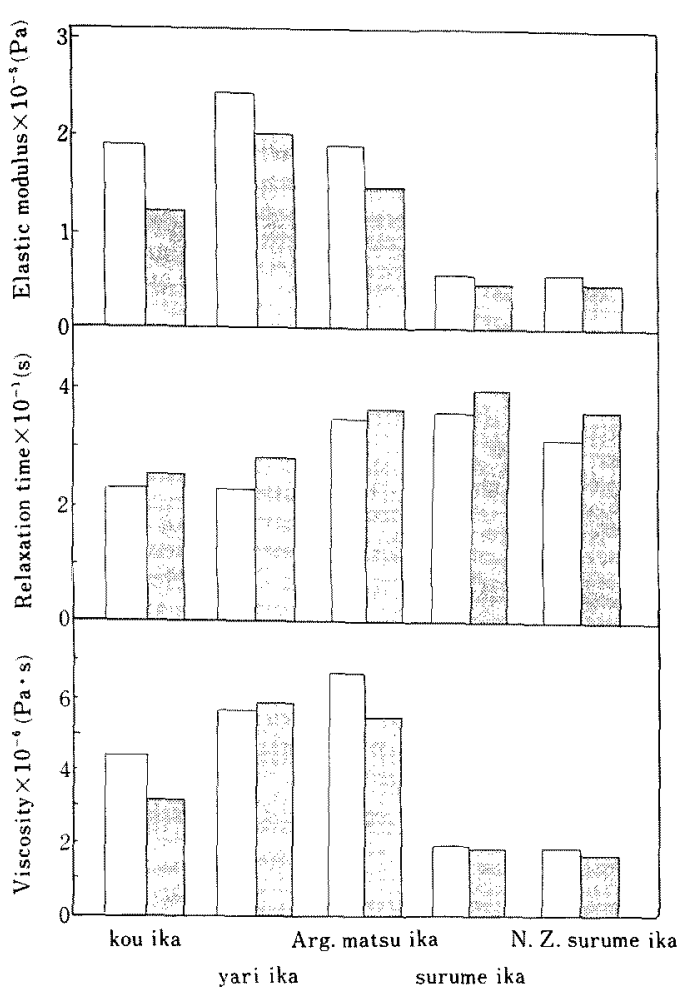

Fig. 4. Rheological properties obtained from stress relaxation tests. The elastic modulus (top), the relaxation time (middle), and the viscosity (bottom) of ika raw meat were measured from the inside of the mantle (left) and from the outside of the mantle (right).

properties obtained from the stress relaxation test, the rupture strength and the rupture power, thus appear to be dependent on the direction of the test.

Although the mantle of "kou ika" was almost the same thickness as that of "surume ika", the relaxation time of "kou ika" was the shortest of all samples, while that of "surume ika" was the longest (middle of Fig. 4). This difference is due to the structure of the skin or muscle in the mantle.

In general, the rupture strength almost corresponds to the hardness of the texture profile, and the rupture power to the toughness. The elastic modulus corresponds to the springiness, and the viscosity to the tenderness. ${ }^{9,10)}$ The values of the rupture power and the viscosity for "kou ika", as shown in Fig. 4 (bottom), were larger than those for "surume ika". Therefore, the raw meat of "kou ika" mantle is tougher and less tender than that of "surume ika" mantle.

\section{Composition of Mantle Meat}

The relationships between the water content or the crude protein content and the rupture power are shown in Fig. 5 (top) and (bottom), respectively. The rupture power of samples except "kou ika" were larger for smaller water content or larger crude protein content. The relationships between the rupture power and the water content or the crude protein content of "kou ika" were distinct from the others. This result suggested that the structure in the mantle of "kou ika" is different from the squid. The microscopic images reveal that the structure of muscle in the mantle of
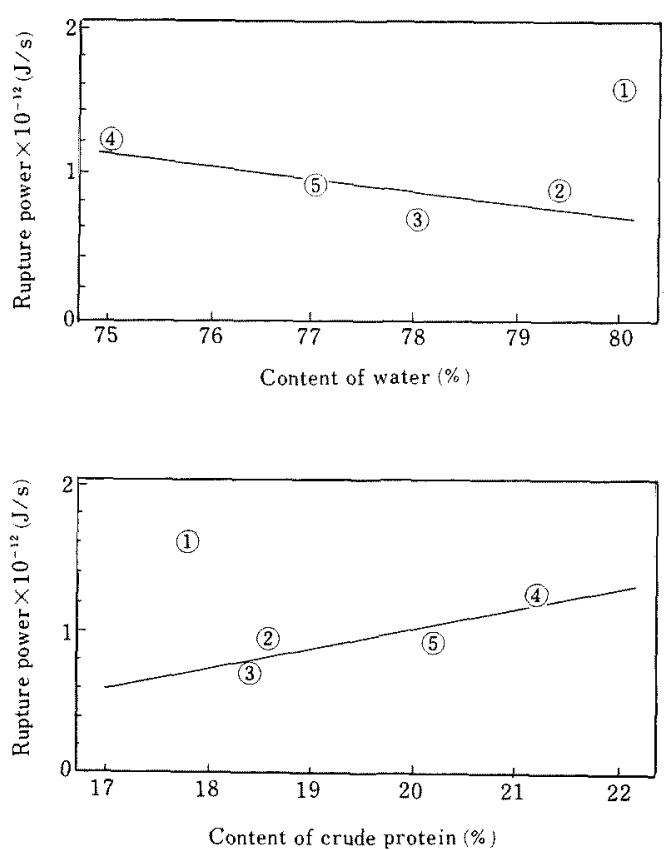

Fig. 5. Relationship between rupture power and content of water (top) or crude proteins (bottom).

Circled numbers indicate the type of "ika" raw meat; "kou ika" (1), "yari ika" (2), "Argentine matsu ika" (3), "surume ika" (4), and "New Zealand surume ika" (5).
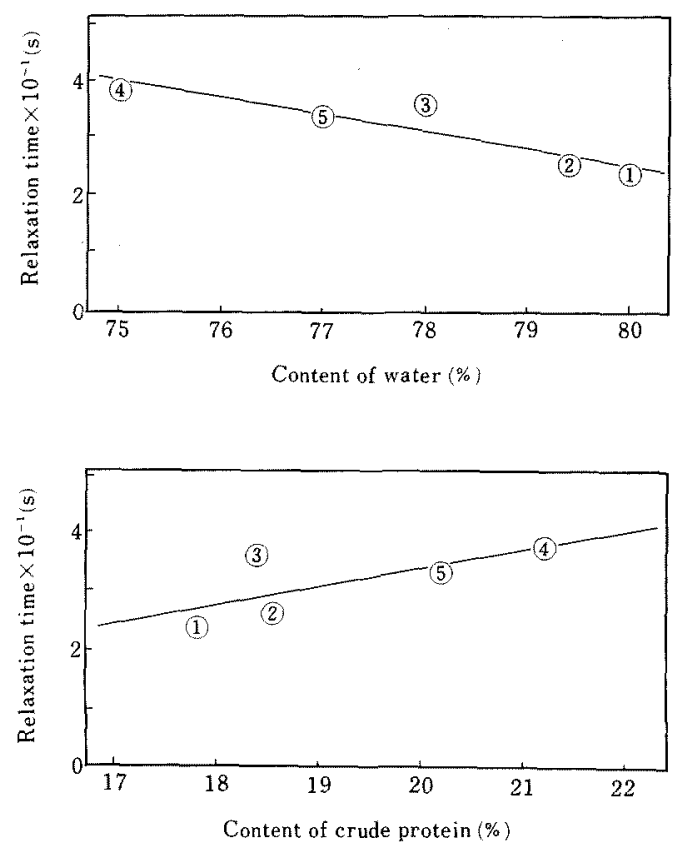

Fig. 6. Relationship between relaxation time and content of water (top) or crude proteins (bottom).

Circled numbers indicate the type of "ika" raw meat; "kou ika (1), "yari ika" (2), "Argentine matsu ika" (3), "surume ika" (4), and "New Zealand surume ika" (5).

"kou ika" is quite different from that in squid. ${ }^{11}$

The relationships between the relaxation time and the water content or the crude protein content were observed as shown in Fig. 6 (top) and (bottom), respectively. The 


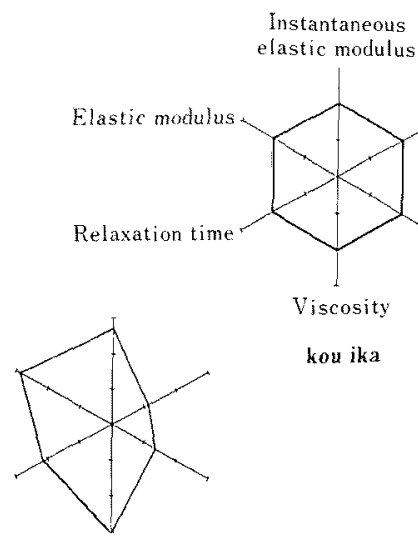

yari ika

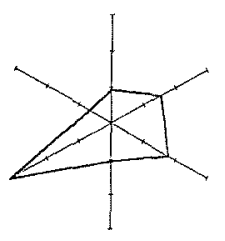

surume ika

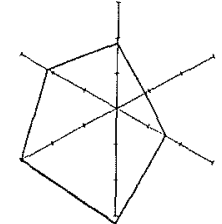

Arg. matsu ika

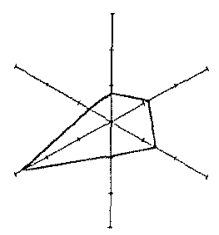

N. Z. surume ika
Fig. 7. Radar charts of the rheological properties of "ika" raw meat. The chart scales show the ratio of the properties of each sample to those of "kou ika".

decreasing water content or increasing crude protein content increased the relaxation time. It is not known whether the relaxation time depends on the water content or crude protein content of the samples in this study. The value of the relaxation time for "kou ika", however, was similar to those for squid, contrary to the values of rupture power. The relaxation time seems to be independent of the structure of the skin or muscle in the mantle, since these tissues in the mantle are not destroyed during the stress relaxation test. On the other hand, the rupture power suffers from the breaking process in the mantle structure.

Figure 7 shows the profiles of the ratio of the rheological properties of each sample based on the values for "kou ika". The values for "surume ika" and "New Zealand surume ika" are very similar, and gave a similar profile of the rheological properties on the radar charts. Both these "surume ika" belong to the same biological species ${ }^{12)}$ while the others exhibited different rheological property profiles since they belong to different species.

In conclusion, the "ika" raw meat different species can be distinguished by measuring its rheological properties.

Acknowledgments This work was supported in part by a Grant-in-Aid for Scientific Research Promotion from the Ministry of Education, Science, and Culture of Japan, for which we are thankful.

\section{References}

1) M. Suyama, S. Kounosu, M. Hamabe, and Y. Okuda: Ika no Riyou. Kouseisya-kouseikaku, Tokyo, 1980, pp. 52-208 (in Japanese).

2) K. Nasu, T. Okutani, and M. Ogura: Ika. Seizan-Do, Tokyo, 1991, pp. 251-294 (in Japanese).

3) T. Tanaka: Histological and histochemical study on processing the spuid meat-I. Histological properties of the squid meat. Bull. Tokai Reg. Fish. Res. Lab., 20, 77-89 (1958).

4) K. Kitabayashi: Biochemical studies on squid-VIII. On the relation of actomyosin to kamaboko-forming ability. Bull. Hokkaido Reg. Fish. Res. Lab., 11, 126-130 (1954).

5) K. Kitabayashi, K. Shudo, and K. Nakamura: Biochemical studies on squid-IX. On the characteristics kamaboko materials. Bull. Hokkaido Reg. Fish. Res. Lab., 11, 131-136 (1954).

6) T. Takahashi and M. Takei: On the toughness of boiled squid meat. Nippon Suisan Gakkaishi, 20, 1015-1019 (1955).

7) M. Shimomura, C. Shimosaka, and J. J. Matsumoto: Changes in texture and proteins of squid meat cured in sake lees. Nippon Shokuhin Kogyo Gakkaishi, 39, 418-424 (1992).

8) A. V. Tobolsky and K. Murakami: Existence of a sharply defined maximum relaxation time for monodisperse polystyrene. $J$. Polymer Sci., 40, 443-456 (1959).

9) W. F. Henry, M. H. Katz, F. J. Pilgrim, and A. T. May: Texture of semi-solid foods-sensory and physical correlates. J. Food Sci, 36, 155-161 (1971).

10) C. Lee, E. M. Imoto, and C. Rha: Evaluation of cheese texture. $J$. Food Sci., 43, 1600-1605 (1978).

11) M. Suyama, S. Kounosu, M. Hamabe, and Y. Okuda: Ika no riyou. Kouseisya-kousikaku, Tokyo, 1980, pp. 38-51 (in Japanese).

12) T. Okutani: Illustrations and description, in "Useful and Latent Cuttlefish and Squids of the World", National Cooperative Association of Squid Processors for the 15th Anniversary of Its Foundation, Tokyo, 1980, pp. 14-58 (in Japanese). 